\title{
SUICIDE ATTEMPT BY SWALLOWING SPONGE OR PICA DISORDER: A CASE REPORT
}

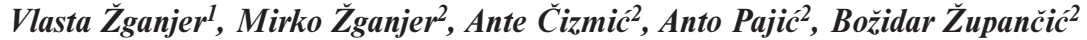 \\ Pfizer d.o.o., Radnička cesta 80, Zagreb, Croatia'; Department of Pediatric Surgery, Children’s Hospital Zagreb, Zagreb, \\ Croatia $^{2}$
}

Summary: Introduction: There are many ways how children with mental illness have actually tried to hurt themselves. Suicidal thinking or attempts always indicate that professional help is needed (2). Every object which can be potential dangerous should be removed but this is very difficult to do. Some of children with these symptoms had Pica diseases. Pica is a medical disorder characterized by an appetite for substances largely non-nutritive (e.g. metal, coal, soil, feces, paper, soap, gum, etc.) or an abnormal appetite for some things that may be considered foods. Material and Methods: The patient swallow sponge from a pillow over a long period of time and she came into our hospital with abdominal pain. She was 16 years old and had abdominal distension, vomiting, abdominal cramping and failure to pass gas or stool. Immediately we suspected mechanical blockade of the intestine. Diagnosis was clinically confirmed by X-rays of the abdomen and with ultrasound. Results: The operative treatment was indicated and we found the proximal bowel distended and the distal segment collapsed. The part of bowel necrosis was removed and anastomosis was done. Conclusion: When patients are determined to attempt suicide or have Pica disorder it is very difficult to prevent.

Key words: Suicide; Foreign body; Pica disorder; Children

\section{Introduction}

Suicide is rare in childhood and early adolescence. Prevention is very important to avoid attempts at suicide. Suicidal thinking or attempts always indicate that professional help is needed (2). In cases where the patient swallows inedible substances we must also suspect Pica diseases. Pica is often developed in people with developmental disabilities, including autism, mental retardation and in children between the ages of two and three. People suffering from mental health conditions like obsessive-compulsive disorder and schizophrenia are also more likely to suffer from Pica (5). Pica is observed more commonly during the second and third years of life and is considered to be developmentally inappropriate in children older than 18-24 months. Research findings indicate that the disorder occurs in $25 \%-33 \%$ of young children and $20 \%$ of children in mental health clinics (9). Among individuals with mental retardation, pica occurs most often in those between the ages of 10-20 years. Pica is often diagnosed in a hospital emergency room, when the child or adolescent develops symptoms of lead poisoning, bowel perforation, or other medical complications caused by the non-food items that have been swallowed (7).

Every object which can be potential dangerous should be removed but this is very difficult to do. Children with mental illness and psychical handicaps have to receive ap- propriate therapy $(1,10)$. Surgical treatment is necessary only in cases with serious complications after swallowing a foreign body.

When a child comes to hospital after bizarre ingestion of a foreign body with acute abdomen, surgical treatment is the method of choice to save the child's life. Children and adolescent suicide attempts are major health problem and should be given high priority with regard to prevention and research.

\section{Case report}

We hospitalized a 16 year-old-girl who said negative things about herself and was self-destructive. She was suffering from abdominal distension, vomiting, abdominal cramping and failure to pass gas or stools. She also constantly repeated that she wanted to die or kill herself. The girl was admitted after swallowing a foreign body but we did not know what she had swallowed. We received information that the girl was prone to occasional swallowing of foreign bodies found in her vicinity but these previous incidences never required surgical intervention. We found out that her mother had also been seriously depressed and had attempted suicide several times. Immediately we suspected mechanical blockade of the intestine. The initial steps were to assess the patient's vital signs, hydration status and cardiopulmonary system. Diagnosis was confirmed upon ab- 
dominal X-rays of the abdomen and by means of ultrasound. On plain X-rays we saw fluid levels in upright views. Sonographic criteria has been established for small bowel obstruction and it is possible to see distended and collapsed bowel segments, free peritoneal fluid, bowel wall edema between the serosa and mucosa and fixed masses of aperistaltic and fluid filled, dilated intestinal loops. First, we treated these condition with bowel rest. Supportive care was done: nasogastric suction, IV fluids $(0,9 \%$ saline or lactated Ringer's solution for intravascular volume repletion) and a urinary catheter to monitor fluid output. Electrolyte replacement should be guided by testing, although in cases of repeated vomiting serum $\mathrm{Na}$ and $\mathrm{K}$ to be depleted. In simple mechanical obstruction, blockage occurs without accumulating above the obstruction. A feculent aspirate is a typical sign of distal small bowel obstruction. When we noticed that ileus was present for several days, a laparotomy was done. Distension was in the terminal ileum in front of the coecum and necrosis of the ileum was found at a length of $15 \mathrm{~cm}$. Bowel necrosis was cut off and we found a sponge which filled up the bowel (Fig. 1). We made endto-end anastomosis between the ends of the bowel. Operative treatment was done without any complications and the girl was in the ICU for three days. On the third post-operative day she had abdominal distension with very strong cramps and without signs of peritonitis. Ultrasound was performed and no pathological signs were found. The signs of the cramps and distension were constantly present for a whole day and when girl had a bowel movement a nurse discovered in the stool two oval ECG monitoring electrodes approximately $4 \mathrm{~cm}$ in diameter. She had swallowed ECG

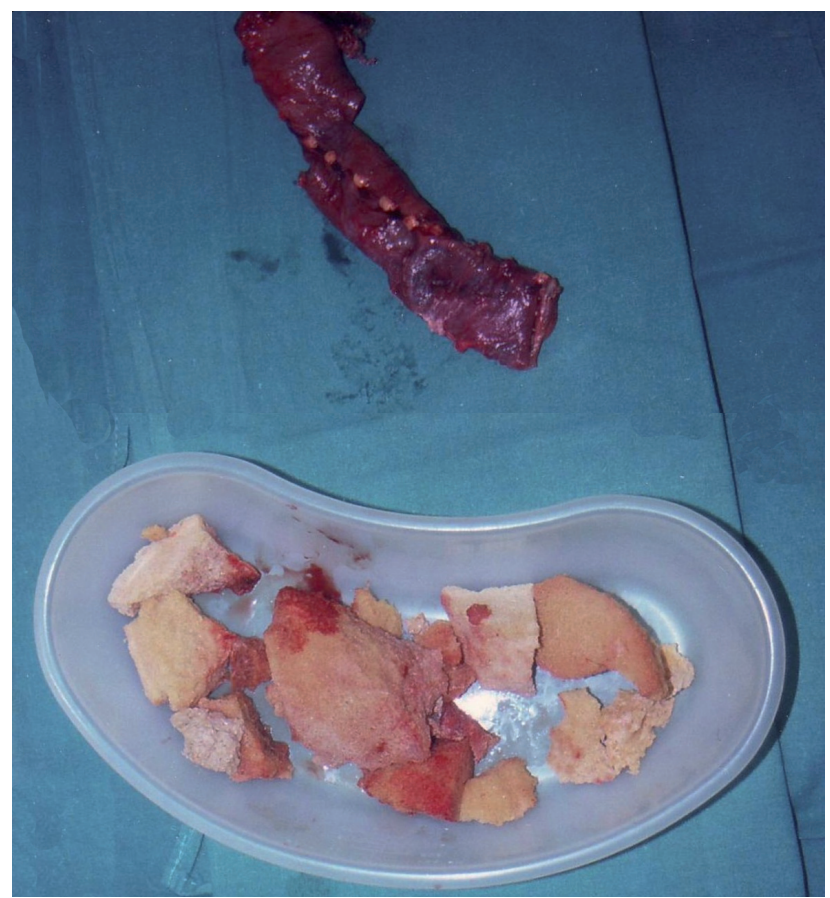

Fig. 1: Bowel necrosis and sponge. electrodes from off her chest. She was unhappy because she had to be in hospital. She said that she swallowed the electrodes because she wanted to injure herself again.

\section{Discussion}

Most children and adolescents who have suicidal tendencies have psychiatric disorders. In such cases prevention is very important, which means putting away all medications in a locked cabinet, removing weapons from the house, and keeping razor blades locked up.. In people with pica disease it is also important to make sure they cannot find anything in their environment which they might swallow in an attempt to injure themselves.

Our patient lives in an institution for children with mental diseases and hospital staff takes care of her 24 hours a day. She was in room with four children with a nurse in the room 24 hours a day. She suffers from a mental illness and receives appropriate therapy. She was sleeping with a spongefilled pillow, in which the sponge could be easily removed.

She swallowed sponge from the pillow over a long period of time and when she had abdominal pain, she came to our hospital and operative treatment was necessary $(11,12)$.

Suicide is rare in childhood and early adolescence (8). Due to the growing risk of suicide with the increase of age, adolescents are the main target of suicide prevention. It is necessary to prevent suicidal thoughts in children being treated for psychiatric disorders. Also in children with pica disease all things that could be swallowed in an attempt at self-harm should be removed from the vicinity. Sometimes it is very difficult to save the lives of children who swallow foreign bodies and develop surgical complications. In our case report, the girl had psychiatric care but she nonetheless managed to swallow a foreign body.

We tried to show the many unusual ways to swallow foreign bodies. Surgical treatment is sometimes not sufficient to save the lives of these children $(3,4)$. Children with psychiatric diseases must to take medication for their psychiatric treatment. Developing efficacious treatment for suicidal children and adolescents would offer better possibilities in the prevention of sucide and the ingestion of nonnutritive substance (6). In such cases, it is difficult to distinguish and decide whether it is a suicide attempt or a pica disorder. The patient said that she wanted to kill herself, but due to her medical condition and previous history of ingestiong foreign objects, we can't be sure that it really was a suicide attempt.

\section{References}

1. Costello EJ, Foley DL, Angold A. 10-year research update review; the epidemiology of child and adolescent psychiatric disorders; II Developmental epidemiology. J Am Acad Child Adolesc Psichiatry 2006;45(1):8-25.

2. Foley DL, Goldston DB, Costello EJ, Angold A. Proximal psychiatric risk factors for suicidality in youth: the Great Smoky Mountain Study. Arch Gen Psychiatry 2006;63(9): 1017-24

3. Kumar CT, Mohan R, Ranjith G, Chandrasekaran R. Characteristics of high intent suicide attempters admitted to a general hospital. J Affect Disord 2006; 91(1):77-81. 
4. Maiss J, Naegel A, Feess G, Hahn EG, Raithel M. Pica syndrome: not only an endoscopic challenge. Gastrointest Endosc. 2005 Jul;62(1):137-8.

5. Martindale JL, Bunker CJ, Noble VE. Ingested foreign bodies in a patient with pica. Gastroenterol Hepatol (N Y). 2010 Sep;6(9):582-4

6. Nordentorf M. Prevention of suicide and attempted suicide in Denmark. Epidemiological studies of suicide and intervention studies in selected risk groups. Dan Med Bull 2007;54(4):306-69.

7. Palmer, Robert L. Helping People With Eating Disorders: A Clinical Guide to Assessment and Treatment. New York: John Wiley and Sons, 2002.

8. Pelkonen M, Marttunen M. Child and adolescent suicide: epidemiology, risk factors, and approaches to prevention. Paediatr Drugs 2003;5(4):243-65
9. Serour F, Witzling M, Frenkel-Laufer D, Gorenstein A. Intestinal obstruction in an autistic adolescent. Pediatr Emerg Care. 2008 Oct;24(10):688-90.

10. Stewards SM, Felice E, Claaseen C, Kennard BD, Lee PW, Emslie GJ. Adolescent suicide attempters in Hong Kong and the United States. Soc Sci Med 2006;63(2):296-306.

11. Tokar B, Cevik AA, Ilhan H. Ingested gastrointestinal foreign bodies: predisposing factors for complications in children having surgical or endoscopic removal. Pediatr Surg Int 2007;23(2):135-9.

12. Yalcin S, Karnak I, Cifici AO, Senocak ME, Tanyel FC, Buyukpamukcu N Foreign body ingestion in children: an analysis of pediatric surgical practice. Pediatr Surg Int 2007;23(8):755-61.

Received: 01/07/2010.

Accepted in revised form: 28/02/2011.

\section{Corresponding author:}

Mirko Žganjer, MD, PhD, Children’s Hospital Zagreb, Klaićeva 16, 10000 Zagreb, Croatia; e-mail: mirko.ganjer@gmail.com 